\title{
BDCC e a Língua Portuguesa no Ensino Médio: Perspectivas, Jnterfaces e Direito Humano
}

\author{
Rosana Helena NUNES* \\ Kleber Aparecido DA SILVA**
}

* É Doutora em Língua Portuguesa e Semiótica - PUC/SP. Pós-Doutorado em Educação - UNICAMP. PósDoutorado em Linguística - UnB

** É Doutor em Estudos Linguísticos (Linguística Aplicada - Língua Estrangeira) na Universidade Estadual Paulista (UNESP - São José do Rio Preto). Pós-Doutor em Linguística Aplicada pela UNICAMP. Pós-Doutor em Linguística Aplicada e Estudos da Linguagem pela PUC-SP. É Pós-Doutor em Linguística pela UFSC.

\begin{abstract}
Resumo:
$\mathrm{O}$ artigo discute a BNCC para o Ensino Médio em Língua Portuguesa, no que concerne às diretrizes para a elaboração de material didático em consonância ao Programa Nacional de Educação em Direitos Humanos (PNDH) na tentativa de pensar o ensino de língua materna, não apenas por meio de diretrizes, mas sim como um direito humano. Escolheu-se, para análise, duas resenhas de livros didáticos, aprovados pelo PNLD em 2021, das editoras brasileiras, FTD e Moderna. O primeiro intitulado Pensar, Sentir e Agir e o segundo, Educação para a Vida. A análise fundamenta-se em princípios norteadores da Pedagogia Crítica Freiriana (FREIRE, 1987; 1992; 1997) e a Linguística Aplicada Crítica (doravante LAC) (PENNYCOOK, 1990; 1998; 1999; 2001; 2006; 2007; PENNYCOOK; MAKONI, 2020) em relação às diretrizes da PNEDH e da BNCC. Na seção 1, privilegiam-se fundamentos básicos da LDB/71, LDB/96, Legislação de 1988 e a PNEDH, para melhor contextualizar o ensino de Língua Portuguesa, alinhados à Pedagogia Crítica Freiriana e à Linguística Aplicada Crítica. Na seção 2, destacamse os princípios norteadores da BNCC e a análise de duas resenhas referentes aos dois livros aprovados no PNLD/2021 para o Ensino Médio de Língua Portuguesa.
\end{abstract}

Palavras-chave:

BNCC; Língua Portuguesa; Ensino Médio.

Signum: Estudos da Linguagem, Londrina, v.24, n.2, p. 112-127, ago. 2021 


\section{BNCC e a Língua Portuguesa no Ensino Médio: Perspectivas, Interfaces e Direito Humano}

Rosana Helena Nunes; Kleber Aparecido da Silva

\section{INTRODUÇÃo}

A finalidade desse artigo é discutir o documento oficial da Base Nacional Comum Curricular (BNCC) para o Ensino Médio em Língua Portuguesa, no que concerne às diretrizes para a elaboração de material didático em consonância com o Programa Nacional de Educação em Direitos Humanos (PNDH) na tentativa de consolidar o ensino de língua materna por meio de diretrizes como um direito humano. Desse ponto de vista, a pretensão é fazer uma análise de duas resenhas de livros didáticos, aprovados pelo PNLD em 2021, de duas editoras brasileiras, FTD e Moderna. O primeiro intitulado Pensar, Sentir e Agir e o segundo, Educação para a Vida.

Essa escolha se deve ao fato de os dois livros aprovados, apresentados no Guia do PNLD/2021, trazerem constructos que vislumbram um ensino baseado na proposta do BNCC. A análise realizada fundamenta-se em princípios norteadores da Pedagogia Crítica freiriana (FREIRE, 1987; 1992; 1997) e da Linguística Aplicada Crítica (PENNYCOOK, 1998; 2001; 2006; 2007; PENNYCOOK; MAKONI, 2020), bem como nas diretrizes da PNEDH e da BNCC, uma vez que se trata de propostas pedagógicas para uma educação emancipatória e humanizadora em Língua Portuguesa.

Freire (1987), em estudos realizados sobre educação emancipatória, reconhece a importância de uma educação em que haja uma situação igualitária em relação à liberdade, no sentido de tornar-se uma superação e não opressão. O diálogo, para Freire, é a condição de prática de liberdade, uma vez que se inicia por meio de uma "inquietação" em torno do conteúdo programático da escola.

Dessa concepção freiriana, a leitura de mundo revela-se como mola propulsora à transformação do ser, na medida em que se adota uma postura humanizadora e emancipatória à aprendizagem do educando, ou seja, a escola tem o papel de humanizar ao educar e transformar os espaços em produção de conhecimento, no que concerne ao processo educativo e à formação humana.

$\mathrm{O}$ artigo apresenta duas seções. $\mathrm{Na}$ primeira seção, privilegiam-se alguns documentos oficiais para melhor contextualizar o ensino de Língua Portuguesa, ao considerar as diretrizes que direcionaram os estudos em língua materna, dentre essas diretrizes, fundamentos básicos da LDB/71, LDB/96, Legislação de 1988 e a PNEDH, alinhados à Pedagogia Crítica Freiriana e à Linguística Aplicada Crítica. Na segunda seção, destacam-se os princípios norteadores da BNCC e a análise de duas resenhas referentes aos dois livros aprovados pelo PNLD/2021 para o Ensino Médio de Língua Portuguesa.

\section{Educação e Direito Humano}

Ao longo da história da educação, o ensino de língua materna esteve voltado a determinadas diretrizes que consideravam o contexto em que o Brasil se situava. A Educação passou por diferentes fases até firmar-se numa educação mais consolidada a práticas não opressoras e mais humanizadoras de ensino de língua. Em documentos oficiais que estabelecem as normativas para o ensino, reportam-se 
à Lei de Diretrizes de Bases de 1971 (LDB/71), quando se considerou, no art.1ㅜㄹ a obrigatoriedade da língua nacional para o ensino de $1^{\circ}$ e $2^{\circ}$ graus (Ensino Fundamental e Ensino Médio).

Art. $1^{\circ} \mathrm{O}$ ensino de $1^{\circ}$ e $2^{\circ}$ graus tem por objetivo geral proporcionar ao educando a formação necessária ao desenvolvimento de suas potencialidades como elemento de autorrealização, qualificação para o trabalho e preparo para o exercício consciente da cidadania.

Nessa época, o governo militar Emílio Médici instituiu a Reforma do Ensino de $1^{\circ}$ e $2^{\circ}$ Graus, depois de tramitação sumária no Congresso. A Lei 5.692 mudou a organização do ensino no Brasil, e o $2^{\circ}$ grau, hoje Ensino Médio, passou a ter como fundamento básico a profissionalização e as escolas públicas e privadas tiveram de se adaptar a essas diretrizes determinadas pelo LDB/71.

Em relação ao estudo da língua materna, a LDB/71 determina que "S $2^{\circ}$ No ensino de $1^{\circ}$ e $2^{\circ}$ graus dar-se-á especial relevo ao estudo da língua nacional, como instrumento de comunicação e como expressão da cultura brasileira". A lei prevê a "comunicação e expressão" como determinante para o ensino da Língua Portuguesa, uma vez que passa a concebê-la no currículo escolar como a disciplina de “Comunicação e Expressão".

Quando a LDB/71 se refere ao currículo, subdivide-o em duas partes: a primeira, formação geral e a segunda, formação especial. Essa formação apresentava duas possibilidades: clássico ou científico. A primeira, voltava-se à área de ciências humanas, a segunda, à área de ciências exatas. Ao final do $2^{\circ}$ grau, o aluno receberia um certificado de habilitação profissional, e essa formação profissional atendia aos interesses do mercado de trabalho e não propriamente à formação humana do indivíduo. Assim prescreve a lei:

$\int 1^{\circ}$ Observadas as normas de cada sistema de ensino, o currículo pleno terá uma parte de educação geral e outra de formação especial, sendo organizado de modo que:

a) No ensino de primeiro grau, a parte de educação gral seja exclusiva nas séries iniciais e predominantes nas finais;

b) No ensino de segundo grau, predomine a parte de formação especial.

$\S 2^{\circ}$ A parte de formação especial de currículo:

a) Terá o objetivo de sondagem de aptidões e iniciação para o trabalho, no ensino de $1^{\circ}$ grau, e de habilitação profissional, no ensino de $2^{\circ}$ grau;

b) Necessidades do mercado de trabalho local ou regional, à vista de levantamentos periodicamente renovados.

A Constituição de 1988, no que tange à língua nacional, no artigo $1^{\circ}$, prevê o direito à educação e corresponde ao fato de esta ser vista também como um direito linguístico, uma vez que se preserva ao cidadão o direito à educação como cidadania e dignidade da pessoa humana.

Art. 1. ${ }^{\circ}$ A República Federativa do Brasil, formada pela união indissolúvel dos Estados e Municípios e do Distrito Federal, constitui-se em Estado democrático de direito e tem como fundamentos: I - a soberania; II - a cidadania; III - a dignidade da pessoa humana; IV - os valores sociais do trabalho e da livre iniciativa; V - o pluralismo político.

Acrescenta-se a isso a Lei de Diretrizes de Bases da Educação de 20 de dezembro de 1996 e suas respectivas ementas parlamentares para educação como direito, já no art. $1^{\circ}$ : 
Art. $1^{\circ} \mathrm{A}$ educação abrange os processos formativos que se desenvolvem na vida familiar, na convivência humana, no trabalho, nas instituições de ensino e pesquisa, nos movimentos sociais e organizações da sociedade civil e nas manifestações culturais.

(...) $₫ 2^{\circ} \mathrm{A}$ educação escolar deverá vincular-se ao mundo do trabalho e à prática social.

Com relação ao parágrafo $2^{\circ}$, a lei prevê que a educação se vincula ao mundo do trabalho e à prática social. Aqui, entra o ensino de língua que necessariamente deve estar a serviço do mundo do trabalho e à prática social. Isso implica em políticas públicas e políticas linguísticas que proporcionem um ensino de língua para inserção do indivíduo ao mundo do trabalho e ao direito à educação de qualidade. Como preconiza a LDB/1996/2017, o direito à educação e a educação como direito humano representa um campo de estudos que tem por preocupação o direito à vida, à cidadania, à questão de gênero, às classes minoritárias.

Em estudos realizados sobre a Educação e Direitos Humanos, Nunes (2019) salienta que a escola corresponde a uma instituição basilar da sociedade, nasce da prática social e reflete as contradições da sociedade de classes. Há uma função política da escola que, por assim dizer, torna-se contraditória, o que leva a conservar e a reproduzir práticas sociais dominantes, espaços hegemônicos de prática escolar voltados aos interesses, não propriamente das classes minoritárias e, sim, da preservação do status quo como práticas colonialistas.

Nunes (2019) assevera que uma proposta de uma prática escolar que privilegie a educação como direito humano é anunciada por meio da proposta de Educação em Direitos Humanos (Plano Nacional de Educação em Direitos Humanos, 2003). Segundo o autor,

(...) é um horizonte novo posto pelas novas concepções voltadas para a Educação e a Escola. A compreensão da Educação como processo de humanização, isto é, de constituição do caráter propriamente humano de nossa necessidade ontológica nos desafia pensar a necessidade de inserir a plataforma de conteúdos e de práticas que se reconhecem como Direitos Humanos no seio desse projeto e desse processo social e cultural (NUNES, 2019, p.35-36).

O estudioso enfatiza o sentido de humanização para se referir a uma educação que busque o propósito da sensibilização, de construção de sentido, da apropriação significativa das informações, dos conhecimentos, das disciplinas ou das áreas temáticas de projeção das características humanas na realidade da sociedade e da natureza. Para Nunes (2019, p. 36),

Humanizar aqui significa ressignificar os saberes, perpassar todo o conhecimento escolar, as práticas e as vivências de aprendizagem na escola, a partir do reconhecimento das premissas filosóficas e jurídicas dos Direitos Humanos. Trata-se de retornar a tese-guia: por força de uma tradição cultural autoritária, excludente e impositiva, somos herdeiros de matrizes culturais e políticas, de sentimentos socialmente valorados marcados pela exclusão, pela competição, pelo egoísmo, pelo narcisismo, pela ganância, pela violência e pela dominação, pela exploração do trabalho, pela superficialidade das leis, pela veleidade dos tratos intersubjetivos e pela falência dos acordos coletivos, para ficar em alguns desses marcos políticos e culturais.

O PNEDH é um documento organizado pelo Ministério dos Direitos Humanos e lançado em 2003. 
[...] está apoiado em documentos internacionais e nacionais, demarcando a inserção do Estado brasileiro na história da afirmação dos direitos humanos e na Década da Educação em Direitos Humanos, prevista no Programa Mundial de Educação em Direitos Humanos (PMEDH) e seu Plano de Ação. São objetivos balizadores do PMEDH conforme estabelecido no artigo 2: a) fortalecer o respeito aos direitos humanos e liberdades fundamentais; b) promover o pleno desenvolvimento da personalidade e dignidade humana;

c) fomentar o entendimento, a tolerância, a igualdade de gênero e a amizade entre as nações, os povos indígenas e grupos raciais, nacionais, étnicos, religiosos e linguísticos; d) estimular a participação efetiva das pessoas em uma sociedade livre e democrática governada pelo Estado de Direito; e) construir, promover e manter a paz. (BRASIL, 2018, p. 10)

Esse documento fundamentou-se na Declaração Universal dos Direitos Humanos da Organização das Nações Unidas (ONU). Essa declaração, de 1948, teve como finalidade uma mudança de comportamento social em relação à produção de instrumentos e mecanismos internacionais de direitos humanos como um processo que resultou em sistemas de proteção dos direitos humanos. Entretanto, uma série de inquietações sobre os direitos humanos, em diferentes esferas da sociedade, vem à tona quando da violação desses direitos, no que tange ao campo dos direitos civis e políticos.

Essa violação de direitos relaciona-se, sobretudo, aos conflitos decorrentes do crescimento da intolerância étnico-racial, religiosa, cultural, geracional, territorial, físico-individual, de gênero, de orientação sexual, de nacionalidade, de opção política, dentre outras, mesmo em sociedades consideradas historicamente mais tolerantes, como revelam as barreiras e as discriminações a imigrantes, refugiados em todo o mundo.

Dadas essas necessidades aparentes da sociedade e a não violação aos direitos humanos, o PNEDH corresponde a um documento que privilegia reportar-se à educação em direitos humanos presente numa cultura democrática, na compreensão dos contextos nacional e internacional, assim como nos valores da tolerância, solidariedade, justiça social, sustentabilidade, inclusão e pluralidade.

Freire (1987; 1992; 1997), em estudos a respeito de práticas de opressão oriundas de uma educação bancária, considera que pensar o mundo é participar de maneira crítica, e a escrita deve estar relacionada não propriamente à repetição e sim às diferentes formas de expressar-se por meio da palavra escrita. Ao conceber a possibilidade de se pensar a educação como uma prática da liberdade, Freire propõe uma pedagogia que foge aos moldes de uma educação bancária, presa aos ditames tradicionais e à repetição e à memorização de conteúdo para o ensino. $\mathrm{O}$ autor admite que o ato de ensinar requer um rigor metodológico e, ao mesmo tempo, libertador em relação ao discurso bancário, uma vez que

Sem bater fisicamente no educando o professor pode golpeá-lo, impor-lhe desgostos e prejudicá-lo no processo de sua aprendizagem. A resistência do professor, por exemplo em respeitar a "leitura de mundo" com que o educando chega à escola, obviamente condicionada por sua cultura de classe e revelada em sua linguagem, também de classe, se constitui em um obstáculo à sua experiência de conhecimento. [...] Respeitar a leitura de mundo, do educando não é também um jogo tático com que o educador ou educadora procura tornar-se simpático ao educando. É a maneira correta que tem o educador de, com o educando e não sobre ele, tentar a superação de uma maneira mais ingênua por outra mais crítica de inteligir o mundo. [...] O desrespeito à leitura de mundo do educando revela o gosto elitista, portanto antidemocrático, do educador que, desta forma, não escutando o educando, com ele não fala. Nele deposita seus comunicados. (FREIRE, 1997, p.138-139) 
Para estudiosos da Linguística Aplicada Crítica (PENNYCOOK, 1990; 1998; 1999; 2001, 2006, 2007; PENNYCOOK; MAKONI, 2020), considera-se, como práticas de opressão, a visão colonial e eurocêntrica para o estudo da língua/linguagem. Daí a ênfase na descolonização da língua como uma forma de "descolonizar" a linguística e a linguística aplicada. A língua, segundo os estudiosos, deve ser vista localmente e não apenas globalmente, ou seja, a autonomia da língua pela própria autonomia para o indivíduo que a utiliza em contextos culturais e sociais característicos. Daí a ênfase na descolonização da língua como uma forma de "descolonizar" a linguística e a linguística aplicada, ou seja, a importância da LAC para a compreensão de uma educação linguística que cumpra o papel de ser emancipatória, libertária e transgressora.

Essa forma de pensar as pesquisas, até então desenvolvidas, como enfoque do Norte Global, o que privilegia pesquisas de cunho colonialista voltadas para a sistematização da língua como manutenção da hegemonia oriunda do colonialismo, preservação do status quo, sem levar em conta a realidade das línguas nos diferentes contextos culturais e sociais como um direito linguístico de preservação dos idiomas e suas características próprias.

Em outros termos, Pennycook e Makoni (2020) enfatizam a necessidade de descolonizar a linguagem, de desvincular a linguagem do pensamento do Norte. Para os autores, a proposta é a de olhar criticamente para os direitos linguísticos e revitalização da linguagem, com o objetivo de se manter caminhos produtivos para alianças entre linguistas, linguistas aplicados, línguas e comunidades.

O PNEDH apresenta a educação em direitos humanos não apenas a uma aprendizagem cognitiva e sim privilegia o desenvolvimento social e emocional. Conforme estabelece o documento,

A educação em direitos humanos deve ser promovida em três dimensões: a) conhecimentos e habilidades: compreender os direitos humanos e os mecanismos existentes para a sua proteção, assim como incentivar o exercício de habilidades na vida cotidiana; b) valores, atitudes e comportamentos: desenvolver valores e fortalecer atitudes e comportamentos que respeitem os direitos humanos; c) ações: desencadear atividades para a promoção, defesa e reparação das violações aos direitos humanos. (BRASIL, 2018, 19)

Em relação aos princípios fundamentais da educação em direitos humanos estabelecidos para a Educação Básica, há de se considerar os seguintes:

[...] • a educação deve ter a função de desenvolver uma cultura de direitos humanos em todos os espaços sociais; - a escola como espaço privilegiado para a construção e consolidação da cultura de direitos humanos, deve assegurar que os objetivos e as práticas a serem adotados sejam coerentes com os valores e princípios da educação em direitos humanos;

- a educação em direitos humanos, por seu caráter coletivo, democrático e participativo, deve ocorrer em espaços marcados pelo entendimento mútuo, respeito e responsabilidade;

- a educação em direitos humanos deve estruturar-se na diversidade cultural e ambiental, garantindo a cidadania, o acesso ao ensino, permanência e conclusão, a equidade (étnico-racial, religiosa, cultural, territorial, físico-individual, geracional, de gênero, de orientação sexual, de opção política, de nacionalidade, dentre outras) e a qualidade da educação;

- a educação em direitos humanos deve ser um dos eixos fundamentais da educação básica e permear o currículo, a formação inicial e continuada dos profissionais da educação, o projeto político pedagógico da escola, os materiais didático-pedagógicos, o modelo de gestão e a avaliação;

- a prática escolar deve ser orientada para a educação em direitos humanos, assegurando o seu caráter transversal e a relação dialógica entre os diversos atores sociais. (BRASIL, 2018, 19-20) 
Dessa perspectiva, o PNEDH corresponde aos procedimentos pedagógicos e agendas que privilegiem uma ação pedagógica conscientizadora e libertadora, que garanta o respeito e a valorização da diversidade, conceitos de sustentabilidade e formação da cidadania ativa. Nunes (2019, p.36-37), ao afirmar que a educação deve ser vista como humanização, reconhece que a escola deve

[...] educar as crianças e jovens para uma nova ética e uma nova estética, marcada pelo respeito à diversidade, pelo cuidado de si, pelo igual respeito e cuidado com a natureza, para a adoção das práticas de sustentabilidade para a preservação da biodiversidade, para a tolerância, para a vivência e defesa do profundo sentimento de solidariedade, para o reconhecimento pleno da dignidade da pessoa humana. Reconhecer o tênue, ainda que incipiente, mas já presente processo ou prática social de "empoderamento" de novos sujeitos, de afirmação dos novos direitos civis, da legitimação de bandeiras e de palavras de inspiração, antes negadas, presentes em projetos sociais, programas e políticas, sociais e públicas, cada dia com maior visibilidade e afirmação é nossa intenção ou anúncio esperançoso.

Ao se referir ao reconhecimento de novos sujeitos que buscam emancipação por meio da prática educacional, Nunes (2019, p. 37) ressalta que a orientação em Direitos Humanos consiste em determinar uma nova configuração de diversidade, seja no campo jurídico, social, cultural e educacional, voltada para a formação de uma sociedade e de uma cultura baseada na igualdade e na solidariedade de todos os homens. [...] "Essa dialética entre a formação da subjetividade no contato significativo com a sociedade se constitui uma nova ontologia da prática social: bumanização e cidadania!”.

O autor reforça que o PNEDH não se trata de uma mera reprodução de leis jurídicas, representação institucional, pressupostas em dispositivos administrativos e curriculares, e sim de princípios políticos que correspondem ao reconhecimento do mundo, da ação do homem na natureza e na sociedade, acima de tudo, refere-se à função social e política da escola, da universidade, do estado, da cultura como condição para a dignidade da pessoa humana, assim como a liberdade e autonomia de cada indivíduo.

[...] Trata-se de buscar outro modo de olhar o mundo, a ciência e a política, capaz de constituir novas estruturas de convivência, de trabalho e de produção de saberes. O Plano Nacional em Direitos Humanos pode constituir os fios de Ariadne a nos auxiliar na saída desse labirinto desumano e violento que nos tem assolada a vida e dilacerada nossa juventude. (BRASIL, 2019, p.51-52)

Pensar a educação brasileira com o propósito da humanização e cidadania compreende uma forma diferenciada da práxis educativa, uma educação para emancipação e humanização da escola básica à universidade. Na segunda seção, o intuito é a de desenvolver um diálogo entre o documento da BNCC em consonância à análise de duas resenhas de livros didáticos, aprovados no Programa Nacional do Livro Didático (PNLD), para melhor elucidar o ensino de língua materna no Ensino Médio.

\section{BCC E PNLD: Diretrizes e AnÁlises de Livros Aprovados}

Nesta seção, a pretensão é analisar dois livros didáticos, aprovados pelo PNLD/2021 - Pensar, Sentir e Agir da Editora FTD e Educação para a Vida da Editora Moderna. A análise fundamenta-se em dois documentos oficinais: BNCC e PNLD.

A BNCC refere-se a um documento, elaborado pelo Ministério da Educação, tem por finalidade a orientação para a Educação Básica no país e divide-se em introdução, estrutura e proposta para o Ensino Médio. Em outros termos, a BNCC define-se como um documento plural e contemporâneo e tem o intuito 
da elaboração dos currículos e propostas pedagógicas para a promoção de uma educação de qualidade, buscando a equidade e a autonomia no que concerne às particulares regionais e locais. Trata-se de

[...] um documento de caráter normativo que define o conjunto orgânico e progressivo de aprendizagens essenciais que todos os alunos devem desenvolver ao longo das etapas e modalidades da Educação Básica, de modo a que tenham assegurados seus direitos de aprendizagem e desenvolvimento, em conformidade com o que preceitua o Plano Nacional de Educação (PNE). Este documento normativo aplica-se exclusivamente à educação escolar, tal como a define o $\ 1^{\circ}$ do Artigo $1^{\circ}$ da Lei de Diretrizes e Bases da Educação Nacional (LDB, Lei nº 9.394/1996), e está orientado pelos princípios éticos, políticos e estéticos que visam à formação humana integral e à construção de uma sociedade justa, democrática e inclusiva, como fundamentado nas Diretrizes Curriculares Nacionais da Educação Básica (DCN). (BRASIL, 2017, p.7)

Esse documento prevê uma análise mais aprofundada sobre as linguagens e seus funcionamentos, a partir de uma perspectiva analítica e crítica da leitura, escuta eprodução de textos verbais e multissemióticos. De acordo com a BNCC, espera-se que o ensino de língua materna, dentro da área de Linguagens e suas Tecnologias, cumpra um papel de levar o aluno à construção e à produção de conhecimento por meio da compreensão crítica e intervenção na realidade, no sentido de uma participação efetiva que contribua à construção da cidadania, do trabalho e dos estudos.

Cumpre lembrar que o aluno se encontra em contato com as mídias digitais e a escola deve corresponder a um espaço de aprendizagem, interação por meio de diferentes práticas de linguagem, uma vez que a cultura digital exige o contato com os novos letramentos e multiletramentos, processos de circulação de informações e a hibridização.

O documento também enfatiza a importância de um avanço nos estudos direcionados à BNCC de Língua Portuguesa para o Ensino Médio em comparação ao Ensino Fundamental. De acordo com a progressão das aprendizagens e habilidades que correspondem ao Ensino Médio, a BNCC apresenta critérios gerais de acordo com o campo de atuação (campo da vida pessoal, campo artístico-literário, campo das práticas de estudo e pesquisa, campo jornalístico-midiático e campo da vida pública). Essas diretrizes buscam propiciar um ensino mais contextualizado por meio de projetos integradores que levam ao desenvolvimento de competências e habilidades dadas as exigências de uma sociedade contemporânea.

Em consonância às diretrizes da BNCC, o Guia do Programa Nacional do Livro e do Material Didático (PNLD/2021) é um documento elaborado pelo Ministério da Educação para subsidiar o trabalho pedagógico por meio de critérios de escolha do livro e do material didático a ser utilizado pelos estudantes do Ensino Médio.

Sob essa diretriz, PNLD/21,

[...] é uma política pública executada pelo FNDE e pelo Ministério da Educação, destinado a avaliar e disponibilizar obras didáticas, pedagógicas e literárias de forma sistemática, regular e gratuita. O PNLD é um dos maiores programas de distribuição de livros do mundo. [...] Com a edição do Decreto $n^{\circ}$ 9.099, de 18/07/2017, os Programas do Livro foram unificados. Assim, as ações de aquisição e distribuição de livros didáticos e literários, anteriormente contempladas pelo Programa Nacional do Livro Didático (PNLD) e pelo Programa Nacional Biblioteca na Escola (PNBE), foram consolidadas em um único Programa, chamado Programa Nacional do Livro e do Material Didático - PNLD. (BRASIL, 2021, p.19)

Esse programa contempla quatro níveis da educação básica: Educação Infantil, Anos iniciais do Ensino Fundamental ( $1^{\circ}$ ao $5^{\circ}$ ano), Anos finais do Ensino Fundamental ( $6^{\circ}$ ao $9^{\circ}$ ano) e Ensino Médio 
e Educação de Jovens e Adultos (EJA). A escolha de livros é realizada por meio de edital de convocação em que as editoras se inscrevem, em prazos definidos pelo FNDE. Após essa etapa, o material didático é disponibilizado para consulta e escolha pelas redes de ensino, uma vez que

do ponto de vista normativo, as obras didáticas seguem um conjunto de princípios éticos e marcos legais para a Educação determinados pelo Edital de convocação No 03/2019 - CGPLI, dentre as quais a Constituição Federal de 1988, a Lei de Diretrizes e Bases da Educação Nacional - LDB (Lei 9.394/1996), a Reforma do Ensino Médio (Lei no 13.415/17), o Plano Nacional de Educação PNE - 2014-2024 (Lei 13.005/2014), o Programa Nacional de Direitos Humanos PNDH-3 (Decreto 7.037/2009), o Estatuto da Criança e do Adolescente (Lei 8.069/1990), as Diretrizes Curriculares Nacionais Gerais para a Educação Básica (Parecer CNE/CEB no7/2010 e Resolução CNE/CEB nº 4/2010) e a Resolução que institui e orienta a implementação da Base Nacional Comum Curricular (CNE/CP No 02/2017). (BRASIL, 2021, p.17)

As obras são analisadas por especialistas antes propriamente de disponibilizar às escolas inscritas no programa. Esses especialistas são responsáveis pelas resenhas críticas para compor o Guia do Livro, material que é disponibilizado para ajudar os professores em sua análise. Para tanto, o programa apresenta uma série de resenhas de obras de Projetos Integradores e de Projetos de Vida, aprovados para o Ensino Médio, com a finalidade de um trabalho interdisciplinar, que atenda ao aprimoramento dos processos de ensino e de aprendizagem para propiciar o desenvolvimento de habilidades e competências dos estudantes. Segundo esse programa,

As obras de Projetos Integradores e de Projetos de Vida foram elaboradas com base nas diretrizes da reforma do Ensino Médio, cujo objetivo é promover uma trajetória escolar que faça sentido para os jovens, que seja capaz de engajá-los em ações transformadoras, estabelecendo diálogo efetivo com seus planos e realizações, ao mesmo tempo que desenvolva conhecimentos, habilidades, atitudes e valores com potencial de os empoderar para lidar com os desafios da sociedade contemporânea. (BRASIL, 2021, p.17)

Ao considerar o material didático de Projetos de Vida, elaborado no intuito da formação do estudante de Ensino Médio, o PNLD/2021 apresenta três dimensões:

[...] (1) a dimensão pessoal, na qual se pretende incentivar o autoconhecimento dos estudantes, para que eles descubram suas aspirações, interesses, potenciais e desafios pessoais; (2) a dimensão cidadã, na qual se objetiva estimular, nos jovens, a ampliação dos seus relacionamentos interpessoais e a adoção de um comportamento respeitoso e ético, na perspectiva das regras de uma boa convivência; (3) a dimensão profissional, na qual se almeja abrir caminhos para que o jovem se encontre como profissional e cidadão. (BRASIL, 2021, p.18)

A dimensão 1 corresponde ao desenvolvimento do estudante nas suas potencialidades e interesses próprios; na dimensão 2, trata-se formas de comportamento em relação à atuação na sociedade. Por fim, a dimensão 3 refere-se à atuação profissional e o caminho a ser percorrido no mundo do trabalho. Considera-se um trabalho de relevância e consistência, quando se possibilita que o estudante de Ensino Médio desenvolva projetos que permitam seu desenvolvimento em diferentes dimensões, ou seja, o trabalho com a linguagem possibilita o próprio exercício de sua cidadania sejam em relação ao autoconhecimento, à atuação como cidadão e a atuação profissional. 
No documento BNCC, o componente Língua Portuguesa - oferecido nos três anos do Ensino Médio (Lei $n^{\circ}$ 13.415/2017) -, salienta a organização por meio de campos de atuação social, sem a indicação de seriação, para melhor dimensionar os currículos e propostas pedagógicas de cada escola. Conforme prevê o documento,

Para orientar uma abordagem integrada dessas linguagens e de suas práticas, a área define que os campos de atuação social são um dos seus principais eixos organizadores. Segundo essa opção, a área propõe que os estudantes possam vivenciar experiências significativas com práticas de linguagem em diferentes mídias (impressa, digital, analógica), situadas em campos de atuação social diversos, vinculados com o enriquecimento cultural próprio, as práticas cidadãs, o trabalho e a continuação dos estudos. (BRASIL, 2017, p.477)

Assim, dessas dimensões apresentadas pelo PNLD/2021, bem com as diretrizes BNCC, apresenta-se a análise de duas resenhas de livros aprovados pelo programa para alunos de Ensino Médio.

\section{Análise de Duas Resenhas de Livros dDidáticos do PNLD}

Essa parte refere-se à análise de duas resenhas a respeito da apresentação de dois livros didáticos, aprovados pelo PNLD/2021 e produzidos por editoras brasileiras, reconhecidas no mercado: FTD e Moderna. Para a aprovação de livros pelo PNLD, abre-se um edital de convocação para que as escolas façam as escolhas dos livros recomendados pelo programa.

No PNLD, evidencia-se o trabalho por meio de projetos integradores e projetos de vida, também salientados na BNCC. O Guia do PNLD/2021 dá ênfase a esse trabalho, ao destacar que

As obras didáticas de Projetos Integradores são compostas por seis projetos, que promovem o desenvolvimento de nove competências gerais da BNCC. Quatro projetos abordam temas integradores obrigatórios (STEAM, Protagonismo Juvenil, Midiaeducação e Mediação de Conflitos) e dois são de livre escolha dos autores. Além dos temas obrigatórios, os projetos precisam abordar ao menos um tema contemporâneo transversal (TCT). Com relação às competências gerais da BNCC, cabe ressaltar nos projetos a ênfase à competência geral 7, "argumentar com base em fatos, dados e informações confiáveis, para formular negociar e defender ideias". Essa competência relacionada à argumentação deve ser trabalhada prioritariamente em todos os seis Projetos Integradores. (BRASIL, 2021, p.15)

Dessa perspectiva, o Ensino Médio passa a ter uma nova forma de conceber a aprendizagem em Língua Portuguesa, uma vez que o trabalho com projetos já por si só remete a um caminho para a pesquisa e que, por assim dizer, envereda-se à construção do conhecimento. Essa construção se dá por meio de uma ação coletiva que permite ao aluno reportar-se à sua história de vida e ao mundo do trabalho.

Nesse sentido, os jovens passam a ocupar lugar estratégico no processo educacional, transformandose no centro do trabalho pedagógico. No novo Ensino Médio, espera-se que a escola se organize para acolher as culturas juvenis atuais e considere os diferentes perfis de seus estudantes, respeitando seus direitos, singularidades, interesses e aspirações. Espera-se igualmente que a escola possa promover o desenvolvimento integral dos estudantes, o que significa contemplar não apenas a formação intelectual, mas também estimular as dimensões física, social, emocional e cultural da aprendizagem, a fim de preparar o alunado para resolver situações corriqueiras, das mais simples às mais complexas, atuar no mundo do trabalho e exercer a cidadania plena. (BRASIL, 2021, p.15) 
Retoma-se aqui a importância de um trabalho com a língua materna com um direito humano, possibilitando ao estudante o exercício pleno da cidadania. Freire (1997, p.28) salienta o erro epistemológico do "bancarismo", ou seja, a prática da educação bancária e adverte:

O necessário é que, subordinado, embora, à prática "bancária", o educando mantenha vivo em si o gosto da rebeldia que, aguçando sua curiosidade e estimulando sua capacidade de arriscar-se, de aventurar-se, de certa forma, o "imuniza" contra o poder apassivador do "bancarismo". Nesse caso, é a força criadora do aprender de que fazem parte a comparação, a repetição, a constatação, a dúvida rebelde, a curiosidade não facilmente satisfeita, que espera os efeitos negativos dos seres humanos - a de se terem tornado capazes de ir mais além de seus condicionantes. Isso não significa, porém, que nos seja indiferente ser um educador "bancário ou um educador "problematizador".

Freire (1997) reforça o fato de que não há docência sem discência, ou seja, o autor ressalta a docência como uma mão dupla em que educador e educando se constituem pela prática educativa, ou seja, as diferentes formas de o educador desenvolver a tarefa de ensinar com rigor metodológico com respeito aos saberes dos educandos.

Essa tarefa de ensinar exige criticidade no fazer pedagógico e didático, bem com requer estética e ética. Nessa dinâmica do ato de ensinar, o comprometimento do educador em aceitar que "correr risco" compreende o processo de aprendizagem na busca da "aceitação do novo" e "rejeição" às diversas formas de discriminação. Reconhece-se, pois, que ainda existem determinadas práticas opressoras no contexto escolar, quando no contato com a diversidade cultural e linguística.

Confirma-se isso, quando o PNEDH reforça que

A educação em direitos humanos vai além de uma aprendizagem cognitiva, incluindo o desenvolvimento social e emocional de quem se envolve no processo ensino- aprendizagem (Programa Mundial de Educação em Direitos Humanos, PMEDH, 2005). A educação, nesse entendimento, deve ocorrer na comunidade escolar em interação com a comunidade local. Assim, a educação em direitos humanos deve abarcar questões concernentes aos campos da educação formal, à escola, aos procedimentos pedagógicos, às agendas e instrumentos que possibilitem uma ação pedagógica conscientizadora e libertadora, voltada para o respeito e valorização da diversidade, aos conceitos de sustentabilidade e de formação da cidadania ativa. (BRASIL, 2018, p.18)

$\mathrm{Na}$ BNCC, a abordagem com relação às linguagens compreende os campos de atuação social, tendo como proposta levar o aluno a vivenciar diferentes experiências no contato com as práticas de linguagem, sejam elas impressas, digitais e analógicas. Diante dessa nova realidade que se desponta com relação aos diferentes recursos multimodais presentes nas esferas da comunicação, é de fundamental importância

[...] propostas de trabalho que possibilitem aos estudantes o acesso a saberes sobre o mundo digital e a práticas da cultura digital devem também ser priorizadas, já que impactam seu dia a dia nos vários campos de atuação social. Sua utilização na escola não só possibilita maior apropriação técnica e crítica desses recursos, como também é determinante para uma aprendizagem significativa e autônoma pelos estudantes. (BRASIL, 2017, p. 478)

Com o intuito de trazer à baila as diretrizes da BNCC, o primeiro livro escolhido para análise é o da Editora FTD e intitula-se Pensar, Sentir e Agir. Como já salientado, essa obra foi aprovada no PNLD/2021 e consta do Guia de Livros Didáticos, estando disponível para a adoção por escolas que oferecem o Ensino Médio. A resenha do $1^{\circ}$ livro apresenta três critérios para o trabalho com a língua 
materna: visão geral, análise e sala de aula. $\mathrm{Na}$ visão geral, a obra se organiza pelo livro do estudante (LE), manual do professor (MP) e material didático do professor (MDP) com três vídeotutorais. Em relação à Língua Portuguesa, a resenha salienta o trabalho com gêneros textuais e recursos multimodais, além da perspectiva para a construção do projeto de vida, linguagem do LE e a parte geral em relação à BNCC. Em relação à diversidade de gêneros textuais e recursos multimodais, o Guia do PNLD dá ênfase não apenas a apresentação do livro com relação ao projeto gráfico, ilustrações, bem como a diversidade de gêneros textuais (reportagens, tirinhas, notícias, etc.) e também reforça a importância das temáticas contemporâneas em relação à formação do estudante de Ensino Médico, o que contempla as habilidades relacionadas às áreas de linguagem de ciências humanas.

No critério de análise, a obra destaca a formação do sujeito em três dimensões: autoconhecimento, expansão e exploração e planejamento. Nesse critério, são apresentadas atividades que propiciam a reflexão pessoal, cidadã e profissional do estudante, além de privilegiar a construção do projeto de vida por meio de atividades que envolvem a reflexão e autoanálise no sentido de maior compreensão em relação ao mundo do trabalho e planejamento estratégico.

Destacam-se, nesse critério, a possibilidade do trabalho com metodologias ativas com intuito de desenvolver a autonomia e o protagonismo do estudante. Ainda no critério análise, o PNLD/2021 reforça o fato de a obra em análise privilegiar a diversidade social, cultural e étnica brasileira em relação à escolha dos textos e fotografias presentes no livro, porém não se considera as diversas línguas oriundas da diversidade linguística presentes no país. Nessa perspectiva, ressalta-se também o respeito da obra com relação às diretrizes e as normas relativas à Educação previstas na Legislação.

[...] a obra promove a conscientização da relação com o outro, apresentando exemplos de superação, bem como a diversidade social, cultural e étnica brasileira por meio de textos e fotografias. Há também a presença de atividades cujo objetivo é desenvolver as habilidades argumentativas dos estudantes e outras que visam a transição entre as dimensões do trabalho com projeto de vida. [...] A obra respeita a legislação, as diretrizes e as normas relativas à Educação. No que se refere à fundamentação teóricometodológica as filosofias essencialista e existencialista estão presentes, mas pouco delimitadas. Isso ocorre porque a obra propõe, a um só tempo, o projeto de vida como uma construção pautada nos aspectos sociais da existência, mas também afirma o reconhecimento da essência humana como a fonte da felicidade. Este aspecto merece a atenção do professor para o desenvolvimento do trabalho. (BRASIL, 2021, 102-103)

Dessa perspectiva, busca-se desenvolver as habilidades necessárias para conhecer, planejar e concretizar o projeto de vida do estudante do Ensino Médio, além da importância fundamental do trabalho com gêneros textuais e textos multimodais. Essa diretriz dialoga com a BNCC, no que diz respeito aos campos de atuação social e as competências e habilidades à formação do estudante, entretanto, a fundamentação teórico-metodológica não foi devidamente explorada, embora essa obra corresponda às diretrizes e normas da legislação. Com efeito, reconhece-se que esse aspecto é abordado de maneira não aprofundada.

Sob essa ótica, acredita-se que todo material didático requer um trabalho do professor em relação àquilo que é apresentado. A educação, como forma de intervenção no mundo, deve estabelecer uma relação de liberdade e autonomia no ato de ensinar. Se houver liberdade e autonomia, exige-se uma tomada de consciência de decisões e uma escuta ativa. E ainda, se houver autonomia, liberdade, consciência e escuta ativa, também reconhecerá que a educação é ideológica, ou seja, requer a participação efetiva do ser educando em diálogo com o educador para reconhecer-se na sociedade como ser pensante e crítico. Para tanto, o diálogo torna-se a mola propulsora que leva o educador a interagir com o educando com amorosidade e respeito. 
Do critério sala de aula, a análise do PNLD/2021 é a de que essa obra apresenta atividades, que levam à autonomia e ao protagonismo do estudante, reforçar a importância da utilização de metodologias ativas em consonância às competências (projeto de vida e mundo do trabalho), bem como o trabalho com a diversidade cultural, social e econômica do país e do mundo, o que contribui para a formação crítica do aluno do Ensino Médio.

A resenha do $2^{\circ}$ livro, Educação para a Vida da Editora Moderna, também é dividida em três critérios: visão geral, análise e sala de aula. No critério visão geral, destacam-se alguns pontos da coleção.

A coleção é composta pelo Livro do Estudante (LE), Manual do Professor (MP) e Material Digital do Professor (MDP), com três videotutoriais. O LE constitui-se de volume único e, a partir de algumas motivações, convida o estudante a elaborar seu próprio Projeto de Vida (PV). O estudante é convidado a construir propósitos: aguçar o olhar para oportunidades, acolher o novo e fazer a diferença no mundo. O MP apresenta diferentes possibilidades de utilização por meio de cronogramas bimestral, trimestral, semestral ou anual. [...] A obra adota uma perspectiva interdisciplinar e considera desejável um professor de postura ativa, um designer de caminhos, um curador de conteúdo, um orientador, um facilitador, um timoneiro, como está descrito na própria obra. (BRASIL, 2021, p.81)

No critério de análise, destacam-se alguns pontos salientados na obra pelo PNLD/2021.

A obra faz opção pelas metodologias ativas, por meio de alguns procedimentos, como a análise de contexto, a escuta e observações criteriosas, a elaboração de registros que documentem os percursos e as reflexões. A integração dessas estratégias oferece possibilidades para o desenvolvimento da consciência de si e do outro, como também oportunidades para aperfeiçoar as habilidades interpessoais, a capacidade de resolver problemas e a postura diante da vida. A obra também enfatiza os procedimentos de investigação por meio de estudos de caso e de imagens, bem como propõe o desenvolvimento de análises por meio do pensamento computacional, com as estratégias de decomposição, reconhecimento de padrões, abstração e pensamento algorítmico. [...] (BRASIL, 2021, p. 82)

Percebe-se que a obra apresenta uma perspectiva interdisciplinar e possibilita um trabalho efetivo do professor como agente do processo, mediador do saber e um colaborador com uma postura ativa. Ainda nesse critério da análise, destacam-se também alguns pontos fundamentais que se relacionam às diretrizes estabelecidas pela BNCC.

A obra destaca o respeito à liberdade e o combate a formas de discriminação, porém nota-se uma lacuna em relação aos povos indígenas, bem como uma carência acentuada de referências bibliográficas de produtores culturais afrodescendentes e de povos originários do território brasileiro. A obra também alerta para a relação entre mundo do trabalho, desenvolvimento tecnológico e desigualdade social. Ao propor essa discussão, enfatiza como os avanços tecnológicos ocasionam mudanças na vida social, econômica e política. Sinaliza ao jovem questões importantes da cultura digital, como a nanotecnologia, a robótica, a inteligência artificial, a indústria 4.0, sem desconsiderar o crescimento da desigualdade social, o meio ambiente em colapso e hostilidades de várias ordens espalhadas pelo planeta. [...] (BRASIL, 2021, p. 82)

$\mathrm{Na}$ análise do PNLD/2021, destaca-se a não relevância aos povos indígenas, embora diz tratar das formas de discriminação, bem como a ausência de literatura que contemple a cultura afrodescendente e os povos originários do território brasileiro. No bojo dessa discussão, é de fundamental importância que 
os materiais didáticos apresentem a literatura comentada e atualizada em relação a um resgate da história desses povos e suas respectivas culturas.

Como já ressaltado, Pennycook e Makoni (2020), em estudos realizados a respeito de visões eurocêntricas para o estudo da língua/linguagem, defendem uma postura decolonial a partir de projetos de linguagem na educação, que busquem apoiar iniciativas de linguagem local, ao apontar para a importância de repensar os quadros que têm informado o trabalho de preservação da língua por tanto tempo. E a reflexão que perpassa pelos estudos realizados pelos autores é a de considerar um olhar mais crítico e, por que não dizer, decolonial para o Sul Global e suas epistemologias voltadas ao ensino de língua/linguagem.

Por fim, no critério sala de aula, retoma-se o trabalho com metodologias ativas e privilegia-se a relação entre mundo do trabalho, desenvolvimento tecnológico e desigualdade social para a construção do projeto de vida por meio de ferramentas que possibilitam o trabalho no contexto de sala de aula.

A partir da análise das resenhas, na obra Pensar, Sentire Agir da editora FTD, há uma ressalva feita com relação à fundamentação teórico-metodológica as filosofias essencialista e existencialista, consideradas como pouco delimitadas. A obra, segundo a análise do PNLD/2021, abrange o projeto de vida como um aspecto social da existência e, ao mesmo tempo, o reconhecimento da essência humana como uma fonte da felicidade. Isso denota que esses dois aspectos são abordados de maneira não aprofundada, o que o educador, quando da análise da obra, deverá atentar.

Em relação à segunda obra, Educação para a Vida, da editora Moderna, contempla-se a construção do projeto de vida por meio de metodologias ativas, no sentido de valorizar o protagonismo dos estudantes, dialogando com as diretrizes da BNCC. Nessa obra, a fundamentação teórico-metodológica corresponde a autores de duas áreas do conhecimento, dentre essas áreas, a da psicologia e a da filosofia. Na parte específica, há orientações para as aulas a serem desenvolvidas. Por fim, a obra apresenta uma bibliografia comentada destinada à formação dos professores no intuito de um trabalho mais profícuo em relação ao desenvolvimento do projeto de vida.

Assim, a análise de duas resenhas mostra que as coleções, aprovadas pelo PNLD/2021, dialogam com as diretrizes da BNCC, no que tange aos critérios adotados para a elaboração das obras, em Língua Portuguesa, destinados aos alunos de Ensino Médio. Cumpre lembrar que o trabalho com a língua materna acontece por meio de práticas pedagógicas efetivas, desde a escolha do material didático até propriamente as diferentes metodologias utilizadas. Daí a importância da escolha de um material, uma coleção aprovada pelo PNLD/2021, que cumpra seu papel de levar o aluno a um desenvolvimento de competências e habilidades no processo de ensino e aprendizagem da Língua Portuguesa.

\section{CONSIDERAÇÕES FINAIS}

Esse artigo teve como objetivo a proposta de uma educação linguística crítica que busque minimizar as desigualdades sociais, ou seja, uma reformulação de propostas curriculares, a partir do documento da BNCC em consonância ao PNEDH, bem como apoiar-se no PNLD para escolha de material didático, em Língua Portuguesa, destinado ao estudante de Ensino Médio na tentativa de pensar o ensino de língua materna, não apenas por meio de diretrizes, mas sim como um direito humano, ou seja, reconhecer a importância de um trabalho efetivo com a língua materna e esta ser vista como um direito humano.

$\mathrm{O}$ artigo apresentou duas seções. Na primeira seção, privilegiaram-se os fundamentos básicos da LDB/71, LDB/96, Legislação de 1988 e a PNEDH, alinhados à Pedagogia Crítica Freireana e à Linguística Aplicada Crítica. Escolheu-se, para análise, duas resenhas de livros didáticos, aprovados pelo PNLD em 2021, das editoras brasileiras, FTD e Moderna. O primeiro intitulado Pensar, Sentir e Agir e o segundo, Educação para a Vida. Para tanto, a análise fundamentou-se em princípios norteadores da 
Pedagogia Crítica Freiriana (FREIRE, 1987; 1992; 1997) e a Linguística Aplicada Crítica (doravante LAC) (PENNYCOOK, 1990; 1998; 1999; 2001; 2006; 2007; PENNYCOOK; MAKONI, 2020) em relação às diretrizes da PNEDH e da BNCC.

$\mathrm{Na}$ seção 1, privilegiam-se fundamentos básicos da LDB/71, LDB/96, Legislação de 1988 e a PNEDH, para melhor contextualizar o ensino de Língua Portuguesa, alinhados à Pedagogia Crítica Freiriana e à Linguística Aplicada Crítica. Na seção 2, destacam-se os princípios norteadores da BNCC e a análise de duas resenhas referentes aos dois livros aprovados no PNLD/2021 para o Ensino Médio de Língua Portuguesa.

Dessa perspectiva, a importância da LAC, em diálogo com a Pedagogia Crítica Freiriana, para a compreensão de uma educação linguística que cumpra o papel de ser emancipatória, libertária e transgressora. Freire (1997, p.15), ao insistir na formação do professor, reconhece que “(...) formar é muito mais do que puramente treinar o educando no desempenho de destrezas (...). Nessa diretriz, o fundamento básico da prática educativa é o de creditar no educador a possibilidade de fazer o educando acreditar que a transformação possa acontecer durante o processo de aprendizagem.

\section{REFERÊNCIAS}

BRASIL. Constituição da República Federativa do Brasil de 1988. Disponível em: http:/ /www.planalto.gov. br/ccivil_03/constituicao/constituicao.htm. Acesso em 28. mar.2020.

BRASIL. LDB: Lei n $n^{\circ}$ 5692/71 de 11 de agosto de 1971. Disponível: https://www.planalto.gov.br/ ccivil_03/leis/15692.htm. Acesso em: 27.mar.2020.

BRASIL. LDB: Lei 9394/96. Lei de diretrizes e bases da educação nacional - edição atualizada. Brasília: Senado Federal, Coordenação de Edições Técnicas, 2017. Disponível: https://www2.senado.leg.br/bdsf/ bitstream/handle/id/529732/lei_de_diretrizes_e_bases_1ed.pdf. Acesso em: 07.abr.2021.

BRASIL. Plano Nacional de Educação em Direitos Humanos. Brasília. Comitê Nacional de Educação em Direitos Humanos. Secretaria Especial dos Direitos Humanos 2007. Disponível: http://portal.mec.gov. br/docman/2191-plano-nacional-pdf/file. Acesso em: 12.ago.2020.

BRASIL. Base Nacional Comum Curricular - Ensino Médio. Brasília/DF. Ministério de Educação e Cultura. 2017. Disponível:http://portal.mec.gov.br/docman/abril-2018-pdf/85121-bncc-ensino-medio/file.

BRASIL. Guia digital PNLD 2021 - Projetos Integradores e Projetos de Vida. Brasília/DF. Ministério de Educação e Cultura. 2021. Disponível: https://pnld.nees.ufal.br/assets-nld/guias/Guia_pnld_2021_ proj_int_vida_Apresentacao.pdf. Acesso em: 05.abr.2021.

FREIRE, P. Pedagogia do oprimido. Rio de Janeiro: Paz e Terra, 1987.

. Pedagogia da esperança. São Paulo: Paz e Terra. 1992.

Pedagogia da autonomia. São Paulo: Paz e Terra, 1997.

NUNES, C. Educação em Direitos Humanos no Brasil Atual: Fundamentos Políticos e Práticas Pedagógicas Possíveis. In NUNES, César Augusto \& GOMES, Catarina (orgs.). Direitos Humanos: Educação e Democracia. Campinas: Brasílica, 2019. p.35-53.

PENNYCOOK, A. Critical Applied Linguistics: a critical introduction, 1, Mahwah, USA: Erlbaum Associates, 2001. 
Uma Linguística Aplicada Transgressiva. Tradução de Luiz Paulo da Moita Lopes. Em: MOITA LOPES, L. P. (Org.). Por uma Linguística Aplicada Indisciplinar. São Paulo: Parábola Editorial, 2006. p. 6784.

A linguística aplicada dos anos 90: em defesa de uma abordagem crítica. In: SIGNORINI, I.; CAVALCANTI, M.C. (Orgs.). Linguística aplicada e transdisciplinaridade. Campinas: Mercado das Letras, 2007 [1998]. p. 23-49

PENNYCOOK, A.; MAKONI, Sinfree. Innovations and Challenges in Applied Linguistics from The Global South. New York, NY: Routledge, 2020.

BRASIL. Reforma tornou ensino profissional obrigatório em 1971. Agência Senado. 27.set.2021. Disponível em: https://www12.senado.leg.br/noticias/materias/2017/03/03/reforma-do-ensino-medio-fracassou-naditadura. Acesso em: 02.abr.2021. 